\title{
Niño-Murcia, M.; Zavala, V. y De los Heros, S. (Eds.). (2020). Hacia una sociolingiíística crítica: Desarrollos y debates. Lima: Instituto de Estudios Peruanos.
}

Esta obra es una compilación de investigaciones tanto teóricas como prácticas que sirven como base teórica y metodológica para una sociolingüística posestructuralista, interdisciplinaria y crítica.

El preámbulo realizado por las editoras, titulado "La sociolingüística crítica: nombrando y situando el campo de estudio", presenta un recuento de la historia de la sociolingüística tradicional y un esbozo de la evolución hacia nuevos conceptos teóricos de corte más crítico.

En la primera sección titulada Desarrollos teóricos se presentan cuatro estudios traducidos del inglés al español de autores representativos del enfoque crítico e ideológico de la sociolingüística moderna. En este apartado encontramos los artículos "De Saussure a la sociolingüística crítica: un giro hacia una perspectiva social del lenguaje", del autor Gunther Kress; "Nuevas coaliciones en la lingüística sociocultural", de las autoras Mary Bucholtz y Kira Hall; "Hacia un enfoque social del bilingüismo", de la autora Mónica Heller, y "Deshaciendo la noción de adecuación: ideologías lingüístico-raciales y diversidad lingüística en educación", de los autores Nelson Flores y Jonathan Rosa.

Los autores y autoras en esta sección proponen un enfoque posestructuralista, es decir, dejar de lado el estudio de códigos lingüísticos entendidos como sistemas autónomos y enfocarse en el estudio de las prácticas lingüísticas y acciones sociales de los usuarios de las lenguas. Para ello, se propone el estudio de la lengua como práctica sociocultural y el estudio del bilingüismo como una ideología subordinada a jerarquías de naturaleza social.

En la segunda sección titulada Problemáticas latinoamericanas se presentan cuatro investigaciones que realizan un análisis crítico y social de problemáticas lingüísticas en contextos sudamericanos. En este apartado encontramos los artículos "Sobre 'lo silencioso' y 'lo bilingüe' en las aulas con niños wichi en la provincia de Chaco", de la autora Virginia Unamuno; "Comunidades de práctica en acción: género, trabajo de imagen y poder del habitus en una comisaría de mujeres y un centro feminista de intervención en momentos de crisis en el Brasil", de la autora Ana Cristina Ostermann; "¿A quiénes les pertenece el maya yucateco? Revitalización y políticas lingüísticas en Yucatán, México", de la autora Anne Marie Guerrettaz, y "¿Códigos o prácticas? Una reflexión sobre el lenguaje desde la educación intercultural bilingüe en el Perú", de la autora peruana Virginia Zavala.

El aporte más destacable de esta obra es la inclusión de las ideologías lingüístico-raciales en el análisis de las prácticas lingüísticas; Nelson Flores y Jonathan Rosa (2015) apuntan al hecho de que las creencias que se tienen sobre las lenguas nunca son neutrales sino, por el contrario, están sesgadas por las relaciones de poder y de desigualdad que se observan en las estructuras sociales donde existen las lenguas y sus usuarios. Por ello, es común que las prácticas lingüísticas de los hablantes de lenguas minorizadas sean evaluadas como "deficientes" por los sujetos oyentes no porque exista una deficiencia real sino por el hecho de que provienen de cuerpos racializados (Flores y Rosa, 2015; Lewis, 2018; Zavala, 2018). Además, cabe destacar que la noción del sujeto oyente blanco que proponen Flores y Rosa para el contexto estadounidense se puede aplicar también a nuestro contexto latinoamericano, donde las lenguas indígenas u originarias son minorizadas y las prácticas lingüísticas de sus hablantes son racializadas por los sujetos oyentes occidentales. Asimismo, los conceptos teóricos propuestos en esta obra sirven para complementar las teorías sustentadas por los Nuevos Estudios de Literacidad (Moreno y Sito, 2019; Zavala et ál., 2004) y el análisis de las prácticas letradas de comunidades racializadas, tales como las comunidades indígenas $u$ originarias y las comunidades afrodescendientes de países latinoamericanos (Flores, 2019; Sito y Kleiman, 2017).

Por último, esta obra sirve para destacar la importancia de la interdisciplinariedad para una comprensión más completa y realista de las prácticas lingüísticas y explica de manera esclarecedora cómo, al cambiar el foco de atención de la manera cómo los usuarios de las lenguas hacen uso de sus recursos lingüísticos hacia la manera cómo estas son percibidas y juzgadas por los grupos sociales privilegiados, se puede lograr una verdadera revaloración de las prácticas lingüísticas de los hablantes de lenguas indígenas u originarias latinoamericanas.

\section{Referencias bibliográficas}

Flores, M. A. (2019). Modelos educativos revisitados y prácticas de literacidad. Revista $X$, 14(3), 67-84. http://dx.doi.org/10.5380/rvx.v14i3.62200

Flores, N. y Rosa, J. (2015). Undoing appropriateness: Raciolinguistic ideologies and language diversity in education. Harvard Educational Review, 85(2), 149-171. https://doi. org/10.17763/0017-8055.85.2.149 
Lewis, M. C. (2018) A critique of the principle of error correction as a theory of social change. Language in Society, 47(3), 325-346. https://doi.org/10.1017/S0047404518000258

Moreno Mosquera, E. y Sito, L. (2019). Discusiones actuales, oportunidades y horizontes en los estudios sobre literacidades en América Latina. Íkala, Revista de Lenguaje y Cultura, 24(2), 219-229. https://doi.org/10.17533/udea.ikala.v24n02a02

Sito, L. y Kleiman, A. (2017). "Esto no es lo mío": Un análisis de conflictos en la apropiación de prácticas de literacidad académica. Universitas Humanística, 83, 159-185. https://doi. org/10.11144/Javeriana.uh83.acap

Zavala, V. (2018). Correcting whose errors? The principle of error correction from an ethnographic lens. Language in Society, 47(3), 377-380. https://doi.org/10.1017/ S0047404518000337

Zavala, V., Niño-Murcia, M. y Ames, P. (Eds.). (2004). Escritura y sociedad: Nuevas perspectivas teóricas y etnográficas. Lima: Red para el Desarrollo de las Ciencias Sociales en el Perú.

\section{Paola Jhong}

Universidad Nacional Mayor de San Marcos, Lima, Perú

Contacto: paola.jhong@unmsm.edu.pe

https://orcid.org/0000-0002-9506-9646 